\title{
Manifesto dos Pioneiros e perspectiva de gênero: Noemy, Cecília e Armanda, as mulheres que impactaram a Educação na década de 1930
}

\begin{abstract}
Resumo
O propósito deste estudo é refletir a respeito do Manifesto dos Pioneiros da Educação Nova de 1932, analisando a papel feminino na cena histórica proposta à reflexão. A pesquisa bibliográfica norteia-se por duas questões: Em que contexto histórico o Manifesto dos Pioneiros foi produzido? Quem foram as três mulheres signatárias de tão importante documento? Os resultados indicam que o Manifesto esteve presente e ajudou a desenhar as iniciativas, as escritas, os desejos das signatárias, que conseguiram transpor as barreiras de serem apenas esposas, mães e senhoras do lar, quer seja por necessidade ou decisão própria, e foram conquistando um espaço maior, passando a ser tratadas politicamente, ocupando cargos que somente homens haviam ocupado na esfera pública e deixando seu legado para a História.
\end{abstract}

Palavras-chave: Educação Nova. Educação-Brasil. Mulheres.
Ana Maria Correa-Silva

Universidade Federal de Mato Grosso do Sul - UFMS - Naviraí/MS

- Brasil

anamariacorreasilva.2004@gmail.co $\mathrm{m}$

Josiane Peres Gonçalves

Universidade Federal de Mato

Grosso do Sul - UFMS - Naviraí/MS Brasil

josiane.peres@ufms.br

\section{Para citar este artigo:}

CORREA-SILVA, Ana Maria; GONÇALVES, Josiane Peres. Manifesto dos Pioneiros e perspectiva de gênero: Noemy, Cecília e Armanda, as mulheres que impactaram a Educação na década de 1930. Revista Linhas. Florianópolis, v. 20, n. 43, p. 272-289, maio/ago. 2019. 


\title{
Manifesto of the Pioneers and gender perspective: Noemy, Cecilia and Armanda, the women who impacted Education in the decade of $1930^{1}$
}

\begin{abstract}
The purpose of this study is to reflect on the Manifesto of the Pioneers of New Education of 1932, analyzing the feminine role in the historical scene proposed the reflection. The bibliographical research is guided by two questions: In what historical context the Manifesto of the Pioneers was produced? Who were the three women signatories of such an important document? The results indicate that the Manifesto was present and helped to design the initiatives, the writings, the wishes of the signatories, who managed to overcome the barriers of being only wife, mother and lady of the home, whether by necessity or own decision, were conquering a a larger space, to be treated politically, occupying positions where only man had occupied in the public sphere and leaving his legacy to history.
\end{abstract}

Keywords: New Education. Education-Brazil. Women.

\footnotetext{
${ }^{1}$ O presente trabalho foi realizado com apoio da Coordenação de Aperfeiçoamento de Pessoal de Nível
} Superior - Brasil (CAPES) - Código de Financiamento 001. 


\section{Introdução}

O presente estudo pretende refletir a respeito do Manifesto dos Pioneiros da Educação Nova de 1932, analisando a papel feminino na cena histórica proposta à reflexão, uma vez que tal escrito pode ser considerado um dos documentos mais importantes no processo de modernização da educação, tendo contado com a assinatura de vinte e seis intelectuais da época, dentre eles, três mulheres que participaram ativamente do processo de reformulação pedagógica iniciado na década de 1920.

O interesse em analisar o papel da mulher no Manifesto dos Pioneiros se deu por considerar esse documento de grande importância para o entendimento, discussão e análise da História da Educação no Brasil e ainda por reconhecer a necessidade de entender o comportamento dessas mulheres e sua postura em um período em que se enfatizava com maior insistência a mulher do lar (NAHES, 2007), como um dos determinantes colaboradores do Estado claramente paternalista e machista, e de uma sociedade falocrática.

Assim, duas questões nortearam a pesquisa: Em que contexto histórico o Manifesto dos Pioneiros foi produzido? Quem foram as três mulheres que assinaram tão importante documento? Para discutir sobre esses questionamentos, o estudo encontra-se dividido em dois momentos específicos: inicialmente, o objetivo é refletir sobre o Manifesto dos Pioneiros da Educação Nova de 1932, contextualizando o tempo histórico em que o mesmo foi originado, distinguindo algumas consequências políticas e sociais alcançadas pelo documento; o segundo momento centrou-se em analisar quem foram as três mulheres que assinaram o Manifesto dos Pioneiros e entender o comportamento destas mulheres e sua postura ante uma época em que era proporcionado somente aos homens o privilégio no desenvolvimento intelectual, social e político.

Para a elaboração deste estudo, utilizou-se pesquisa bibliográfica fundamentada principalmente em autores como Saviani (2007), Oliveira (2016), Nahes (2007), Ramos (2005), Xavier (2002) entre outros, que abordam O Manifesto dos Pioneiros e as signatárias de tal documento. 
Ao refletir sobre a pesquisa bibliográfica, Ruiz (1996, p. 12) enfatiza que “[...] consiste no exame do material teórico, para levantamento e análise do que já se produziu sobre determinado assunto que se tem como tema de pesquisa científica”.

Para Gromoviski e Silva (2014, p. 1), o objetivo principal da análise bibliográfica é saber sobre as diferentes contribuições das pesquisas científicas disponíveis sobre determinado assunto. "Ela dá suporte a todas as fases de qualquer tipo de pesquisa, uma vez que auxilia na definição do problema”. Para a realização da presente pesquisa, são utilizados artigos, revistas e sites da internet que tratam da temática investigada.

\section{Alguns aspectos históricos do Manifesto dos Pioneiros}

Ao povo e ao Governo, o Manifesto dos Pioneiros da Educação Nova foi um documento publicado em meados de 1932, pelo sociólogo Fernando de Azevedo, contando com a assinatura de vinte e seis personalidades que assumiram o encargo de encaminhar o Brasil à modernidade através da Educação, tornando-se referência para a renovação educacional do Brasil (SAVIANI, 2007).

O documento expõe um importante momento da história política, social, cultural e educacional do Brasil, evidenciando o movimento renovador que já havia se iniciado na década de 1920. Segundo Oliveira (2016, p. 81), “A década de 1920 foi marcada por inúmeros debates sociais e educacionais que vislumbravam uma mudança radical no país, e independente de sua matriz filosófica, os grupos envolvidos tinham a compreensão da necessidade da mudança”. As mudanças que movimentavam o país eram consequências das discordâncias vividas pela sociedade brasileira, em que “[...] as camadas populares viviam afundadas num analfabetismo, hábitos de higiene inadequados e pouca preparação profissional e intelectual para intervir no processo produtivo" (OLIVEIRA, 2016, p. 58). Também Lemme (1984, p. 258) salienta que “[...] as poucas escolas públicas existentes nas cidades eram frequentadas pelos filhos das famílias de classe média".

No entanto, era nesse mesmo contexto que se iniciava um vasto processo referente à mudança da base econômica brasileira, marcado pela transição do modelo agrário-exportador para o modelo urbano-comercial (OLIVEIRA, 2016). Todavia, essa caminhada exigia dos trabalhadores a qualificação. 
Assim sendo, constata-se que o texto do Manifesto foi escrito numa atmosfera de descontentamento dos pensadores brasileiros, que buscavam indicar soluções para os problemas nacionais. $O$ enquadramento da memória operada no Manifesto se dá pela ordenação do tempo histórico estabelecendo uma hierarquia temporal na qual o passado é avaliado com base na idéia de ausência, o presente é interpretado como um hiato, uma transição - porque um momento de crise que evidencia a necessidade de intervenção das elites intelectuais e, finalmente, o futuro, projetado com base no programa de renovação educacional, aponta para a construção do Brasil moderno. (XAVIER, 2002, p. 39)

É possível afirmar que os primeiros passos para a execução prática de uma política educacional tiveram início com as reformas ocorridas na década de 1920, dentre elas destacam-se: Reforma Sampaio Doria, em São Paulo, de 1920; Reforma Lourenço Filho, no Ceará, em 1922; Reforma Anísio Teixeira, na Bahia em 1924; Reforma Educacional no Rio Grande do Norte, em 1924; Reforma Fernando de Azevedo, no Distrito Federal, em 1927; Reforma Francisco Campos, em Minas Gerais, em 1927; Reforma Educacional no Espírito Santo em 1928, sob a direção de Atílio Vivacqua (OLIVEIRA, 2016).

Os responsáveis por essas reformas foram pessoas notáveis do meio político que se inspiravam no movimento de renovação pedagógica na Europa e nos Estados Unidos, especialmente nas ideias escolanovistas deweyanas. Desse modo, anos mais tarde, impulsionadas pela participação de outros educadores, essas reformas acabaram por estabelecer o grupo dos pioneiros da educação nova que por meio do manifesto, lançaram as bases para a mudança da educação brasileira (OLIVEIRA, 2016).

O Manifesto foi lançado em 1932, como resultado da IV Conferência Nacional de Educação, organizada pela Associação Brasileira de Educação (ABE). Para Saviani (2007, p. 229), a Associação Brasileira de Educação foi criada como uma organização nacional, por iniciativa de treze intelectuais cariocas que "[...] a princípio tinha a finalidade de organizar um partido do ensino, no entanto acabou se estabelecendo como órgão apolítico, dedicado a abranger todos os envolvidos na causa da educação". De acordo com Lemme (1984, p. 261),

A Associação Brasileira de Educação ( $A B E)$, onde se congregaram educadores brasileiros mais eminentes e atuantes, desde sua fundação em 1924, assumiu a liderança de todos esses movimentos de renovação e educação de palestras, debates, cursos e conferências, convocando para isso autoridades e especialistas nacionais e estrangeiros. 
A ABE alcançou amplo destaque político; a sessão de inauguração da IV Conferência de Educação contou com a participação do Ministro Francisco Campos e do Presidente Getúlio Vargas. Entretanto, foi a atuação de Nóbrega da Cunha que obteve maior relevância, uma vez que ele encaminhou à assembleia da IV CNE, um requerimento solicitando a redação de um manifesto que servisse de base para o governo, tornando-se, a partir daí, o principal articulador da produção do Manifesto (SAVIANI, 2007).

Ademais, o presidente da Conferência, Fernando Magalhães, passa essa incumbência para Fernando de Azevedo "[...] que deveria aceitá-la em nome do Governo, da imprensa e do povo" (XAVIER, 2002, p. 21). É possível perceber que a formação dos pioneiros da educação nova é produto de um movimento nacional, que teve nas reformas educacionais espalhadas por todo o país, contribuição para concretizar uma liderança política com suporte para conduzir o projeto de modernização (OLIVEIRA, 2016).

Trazendo consigo uma visão educacional moderna, a Educação Nova proposta pelos pioneiros se fundou embasada em princípios de ética nas relações sociais, com valores de autonomia, respeito à diversidade, igualdade, liberdade e solidariedade. De fato, tal proposta educacional causou grandes repercussões na sociedade, visto que:

[...] os pioneiros propunham: um conjunto de medidas práticas pelas quais se pretendia fundar um novo sistema educacional - único, de base cientifica e sob a responsabilidade do Estado. O plano de reconstrução educacional previa ainda a laicização do ensino e a co-educação, introduzindo dessa forma, valores realmente inéditos na estrutura educacional da época. (XAVIER, 2002, p. 48)

A laicidade do ensino pode ser associada a um dos pontos de maior conflito exposto no Manifesto. Para Saviani (2007, p. 257), “[...] conforme os católicos, a escola leiga preconizada pelos escolanovistas em lugar de educar deseduca: estimulava o individualismo e neutralizava as normas morais, incitando atitudes negadoras da convivência social e do espírito coletivo". Já os Escolanovistas defendiam a laicidade como um enfoque que representava um componente fundamental, na medida em que colocavam em prática os princípios democráticos de liberdade de pensamento e credo, neutralizando assim a atuação da Igreja Católica, que exercia grande influência no campo educacional. 
No projeto do Manifesto, o Estado desempenhava um papel fundamental, por ser entendido como a esfera superior, capaz de oferecer à educação uma natureza social obrigatória e pública. Nesse sentido, a educação gratuita e de qualidade seria estendida a todos os sujeitos, sendo então propagada a universalização da educação (SAVIANI, 2007). A ideia de uma escola pública financiada pelo Estado retiraria das mãos da Igreja o poder de controlar o ensino.

Diante do exposto, e antes de abordar o Manifesto dos Pioneiros e as relações de gênero, cabe refletir sobre o que postula Oliveira (2016, p. 82) a respeito da educação brasileira na terceira década do Século XX:

O lançamento do Manifesto dos Pioneiros lançado em 1932 representou a tentativa de criar uma política educacional que fosse estimulada em todo o território nacional, tendo na figura do estado os papeis de promover e disseminar a nova educação que traria ao país a modernidade e o progresso econômico, social e político.

\section{As mulheres no Brasil na década de 1930}

Apesar das mudanças ocorridas no Brasil na década de 1930, no que se refere ao gênero feminino, o país experimentava uma pausa ou até mesmo um retrocesso, dado que a política tradicionalista, bem como a ditadura do Estado Novo, preocupavam-se em manter a mulher presa ao lar, cuidando da casa e de sua família. Para Zimmerman (2005), historicamente, coube às mulheres apenas o papel de mãe e de esposa dedicada, restringindo-as à função caseira e materna, enquanto que aos homens foram atribuídos papéis no espaço público e político, sendo a eles atribuído o poder.

Trata-se de um período histórico caracterizado pelo autoritarismo, em que predominava a dicotomia entre a mulher do lar e a mulher prostituta; a desvantagem do trabalho fora do lar e a valorização do trabalho do lar, do cuidado com os filhos e marido, entre outras. Dessa maneira, existia ainda um quadro variado de estereótipos que caracterizam as mulheres como menos capacitadas, ocasionando, por exemplo, padronizações referentes aos tipos de profissões consideradas masculinas e femininas, dificultando, entre outras coisas, as suas oportunidades de entrada ou ascensão no mercado de trabalho (BELO; CAMINO, 2010). 
O direito ao voto e à profissão de professora de primeiras letras - "as normalistas" - significavam as únicas conquistas sociais consentidas, dado que guardavam o aspecto da mulher educadora de crianças, enquanto que as carreiras de professor de segundo e terceiro graus eram, predominantemente, exercidas por homens (NAHES, 2007).

O projeto do Plano Nacional de Educação... Previa a existência de um ensino dito 'doméstico', reservado para meninas entre 12 e 18 anos, e que equivaleria a uma forma de ensino médio feminino. Seu conteúdo era predominantemente prático e profissionalizante, e fazia parte, no plano, do capítulo destinado ao ensino da "cultura de aplicação imediata à vida prática ou ao preparo das profissões técnicas de artífices". Era, pois, destinado principalmente a mulheres de origem social mais humilde, ainda que pudesse atrair também mulheres de origem social mais elevada, que dessa forma poderiam manter-se em regime escolar estritamente segregado. Segundo o plano, o ensino feminino se dividiria em doméstico geral (dois ciclos), doméstico agrícola (também dois ciclos) e doméstico industrial. O primeiro ciclo prepararia as mulheres para a vida no lar, o segundo formaria as professoras para esse sistema. (SCHWARTZMAN; BOMENY; COSTA, 2000, p. 108)

A ideia predominante na década de 1930, era de que se as mulheres servissem a família, estariam consequentemente servindo à pátria. Dessa forma, enquanto elas se mantinham desinformadas do contexto político, indiferentes aos problemas sociais, inteiramente voltadas para as questões domésticas e familiares, não interferiam nas decisões masculinas e da nação (NAHES, 2007).

Entretanto, algumas mulheres que pertenciam ao mesmo contexto histórico e cultural brasileiro, que não precisavam se envolver com questões educacionais, culturais ou sociais, conseguiram transpor as barreiras de serem apenas esposas, mães e senhoras do lar, quer seja por necessidade ou por decisão própria, para então conquistarem um espaço maior na esfera pública, deixando assim seu legado para a História.

\section{Noemy Marques da Silveira Rudolfer}

Noemi Marques da Silveira Rudolfer nasceu no dia 8 de agosto de 1902, em Santa Rita do Viterbo, São Paulo. Existem poucos dados sobre sua família; o que se sabe é que eram quatro irmãs, Itacy, Ana, Iracema e Noemy. Porém, existem fortes indicativos que os pais de Noemi eram pessoas de mente aberta, esclarecidas, que estavam à frente de 
seu tempo, distinguindo-se dos costumes da época, no que se refere a limitações do papel da mulher no contexto social, pois suas filhas estudaram e puderam se dedicar a uma profissão (RAMOS, 2005).

Impulsionada por essa incitação familiar, Noemy, antecipadamente, aos 16 anos de idade, alcança o título de "Professora do Ensino Primário" na tradicional Escola Normal Padre Anchieta, lugar onde os estudos estavam voltados para o interesse pela Psicologia Educacional, área nuclear de sua formação acadêmica. Logo após, ela foi assistente de Lourenço Filho, personagem importante em seu processo de desenvolvimento profissional.

[...] por incentivo de Lourenço Filho, ela encontrava-se estudando no Teacher's College da Universidade de Columbia, quando o mesmo Lourenço a chamou para organizar o apoio psicopedagógico ás escolas, implantando o Serviço de Psicologia Aplicada. (SAVIANI, 2007, p. 237)

Dessa maneira, condecorada com bolsa de estudos para os Estados Unidos, fato inédito para as mulheres de sua época, Noemy teve a chance de estudar em uma universidade de renome e de ser aluna de grandes líderes da Psicologia. Em 1931, Fernando de Azevedo a convidou para subscrever o Manifesto dos Pioneiros da Educação Nova, indicando-a mais tarde para substituir Lourenço Filho na cadeira de Psicologia Educacional do Instituto Pedagógico, novo nome que a reforma de Lourenço Filho deu a Escola Normal de São Paulo (SAVIANI, 2007).

Em 1932, Noemy se afastou do Serviço de Psicologia Aplicada por discordar das novas diretrizes surgidas com a entrada de Sud Mennucci na Diretoria Geral de Ensino de São Paulo. Em 1933, no entanto, quando Fernando de Azevedo tomou a frente da Diretoria Geral de Ensino, a educadora retomou o seu cargo (RAMOS, 2005).

A educadora então dirigiu serviços de orientação educacional junto ao Instituto de Seleção e Orientação Profissional (ISOP) da Fundação Getúlio Vargas e de outras importantes instituições de ensino no Rio de Janeiro, onde colaborou para o desenvolvimento da Psicanálise, tanto na qualidade de analista pessoal, quanto na de analista didata, desenvolvendo vários seguidores nessa área, quiçá os primeiros do país. 
A atuação de Noemy não se restringiu apenas a Universidade de São Paulo, mas se estendeu a outras regiões do país, como também do exterior, aceitando convites para missões culturais do Ministério de Relações Exteriores em vários países da América Latina, instituindo também contatos pessoais com grandes líderes da ciência psicológica em visita a diversos países da Europa (RAMOS, 2005).

Todavia, apesar de tantas conquistas em sua vida profissional, Noemy, na condição de mulher, viveu em uma época em que, especialmente nos anos de sua maior produção profissional, era proporcionada aos homens a primazia no desenvolvimento intelectual. Tal realidade talvez explique o fato de Noemy, ou Prof ${ }^{a}$ Noemy, se afastar por longos períodos e se aposentar precocemente aos 52 anos de idade.

No entanto, mesmo após sua aposentadoria, Noemy continuou ativa, proferindo conferências e ministrando cursos de extensão universitária em instituições brasileiras, como também escrevendo artigos em revistas especializadas, cujo legado de produção científica completa um total de 200 publicações (RAMOS, 2005).

Existem muitos dados a respeito da vida profissional de Noemy e pouco sobre sua vida pessoal. Ainda assim, é possível afirmar que se trata de uma mulher que estava à frente de seu tempo; para comprovar este fato, basta reconhecer a presença extraordinária da educadora, a única catedrática entre os catedráticos e assistentes do sexo masculino, para poder apontá-la como pioneira. Em 16 de dezembro de 1980, morre Noemy Silveira Rudolfer, aos 78 anos.

\section{Cecília Bernevides de Carvalho Meireles}

Cecília Benevides Carvalho de Meirelles nasceu em 7 de novembro de 1901 na Tijuca, Rio de Janeiro. Órfã de pai e de mãe, foi criada pela avó, Jacinta Garcia Benevides. Concluiu seus primeiros estudos (curso primário) em 1910, na Escola Estácio de Sá e recebeu de Olavo Bilac, Inspetor Escolar do Rio de Janeiro, medalha de ouro por ter feito todo o curso com “distinção e louvor”. Em 1917, Cecília diplomou-se pela Escola Normal do Largo do Estácio e passou a exercer o magistério primário em escolas oficiais do antigo Distrito Federal (MORAES, 2008). 
No início de sua carreira como escritora, precisamente no ano de 1922, Cecília Meireles começou a participar de uma corrente literária chamada de "espiritualista", caracterizada por poemas de linguagem religiosa, voltados ao catolicismo. Nesse mesmo ano, casou-se com um pintor português, com que teve três filhas: Maria Elvira, Maria Mathilde e Maria Fernanda (MORAES, 2008).

Aos 28 anos, prestou concurso para lecionar literatura vernácula na Escola Normal do Distrito Federal com a tese Espírito Vitorioso, tendo seu texto classificado em segundo lugar. Dirigiu a "Página de Educação", no Jornal Diário de Notícias do Rio de Janeiro. Nesse período, teve a oportunidade de conviver com Nóbrega da Cunha, outro signatário dos Pioneiros e fundador do referido jornal (MORAES, 2008).

No ano de 1933, Cecília participou da gestão de Anísio Teixeira na Diretoria de Instrução Pública e teve a oportunidade de criar a primeira biblioteca infantil do Rio de Janeiro, que funcionou até 1937, e ficou conhecida como Pavilhão Mourisco (MORAES, 2008). No curto espaço de tempo de sua existência (1934-1937), a Biblioteca Infantil do Pavilhão Mourisco foi um espaço que contribuiu para estimular e difundir a cultura, a partir de uma ideia considerada inovadora para a época: as estantes tinham altura apropriada e acessível aos olhos e mãos infantis, e havia a possibilidade de acesso sem o acompanhamento de adultos, tornando-se um espaço de leitura atraente para as crianças (PIMENTA, 2001).

Cecília Meireles foi outra mulher apaixonada pela educação, mas não por qualquer tipo de proposta educativa, visto que acredita na perspectiva da Escola Nova e foi essa paixão que motivou sua campanha no meio jornalístico. Mesmo antes do lançamento do Manifesto, a intelectual utilizava o espaço do jornal para apoiar a Reforma de Fernando de Azevedo no Distrito Federal, defendendo a necessidade de inovação no entendimento educacional (MORAES, 2008).

Cecília, de forma semelhante aos demais educadores envolvidos no Manifesto, também alimentou expectativas no que se refere à Revolução de 1930. Abriu espaço singularizado na coluna "Comentário" para a difusão das ideias escolanovistas. Neste tempo, os defensores da educação tradicional propagavam que a escola deveria ser separada da realidade. Não obstante, a intelectual discutia a necessidade de a escola adentrar na vida. 
Numa época de forte efervescência política, Cecília, como jornalista e educadora, registrava impressões e críticas sobre os acontecimentos, colocando-se como uma pessoa ativa ao lado dos intelectuais do momento. Ela foi a primeira voz feminina de grande expressão na literatura brasileira, com mais de 50 obras publicadas, entre elas: 0 livro Espectros, que escreveu ainda muito jovem, com apenas 18 anos; Nunca Mais... e Poema dos Poemas; Baladas Para El-Rei; Mar Absoluto; Viagem; Romanceiro da Inconfidência; Pístoia, Cemitério Militar Brasileiro; A Rosa; Ou Isto Ou Aquilo, enfim (MORAES, 2008).

Cecília viveu intensamente a literatura e a educação no Brasil, e também fora do dele, realizando várias viagens aos Estados Unidos, Europa, Ásia e África, fazendo conferências sobre literatura, educação e folclore; lecionou Literatura e Cultura Brasileira na Universidade do Texas; proferiu, em Lisboa e Coimbra, conferência sobre Literatura Brasileira. Publicou em Lisboa o ensaio Batuque, Samba e Macumba, com ilustrações de sua autoria.

Em seu caminho, Cecília encontrou algumas adversidades, porém nunca abandonou uma atitude otimista relativa ao ser humano e à Escola Nova Morreu no dia 9 de novembro de 1964 a autora, jornalista, poetisa, educadora e uma das signatárias do Manifesto dos Pioneiros. Foi homenageada pelo Banco Central, em 1989, com sua efígie na cédula de cem cruzados novos (MORAES, 2008).

\section{Armanda Álvaro Alberto}

Armanda Álvaro Alberto nasceu no Rio de Janeiro em 10 de junho de 1892. Filha de Maria Teixeira da Mota e Silva e de Álvaro Alberto Silva (SAVIANI, 2007). Nem ela e nem seu único irmão, Álvaro Alberto da Mota e Silva, frequentaram escolas na infância, pois a mãe se responsabilizou por sua educação escolar. Filha de família de classe média alta, Armanda deste muito cedo teve contato com um ambiente intelectual, o que lhe possibilitou acesso a grande requinte cultural (MIGNOT, 2010).

No ano de 1912, já com 20 anos, ingressou no curso especial de literatura do Colégio Jacobina, reconhecido na época pela atitude inovadora de seus métodos de ensino, o que lhe permitiu aperfeiçoar os conhecimentos adquiridos sob a orientação de 
sua mãe e de professoras particulares. Foi nesse mesmo colégio, por volta de 1917, que Armanda começou a traçar a sua carreira na área do magistério (MIGNOT, 2010).

Acompanhada pelo irmão que havia assumido um posto da Marinha, Armanda mudou-se para Angra dos Reis, local em que deu forma a um projeto de escola ativa, em que a criança era considerada o centro do processo do ensino-aprendizagem, nos moldes do que vinha sendo feito em países europeus. Apenas com uma mesa grosseira e esteira no chão, provou um novo estilo de educar: respeitando a liberdade, a atividade e o interesse dos alunos e alunas, filhos de pescadores.

Em Angra dos Reis, improvisou apenas uma escola ao ar livre, à sombra de bambus, com mobiliário bem tosco: uma única mesa de pinho, uma cadeira e esteiras no chão. Cerca de cinqüenta crianças da região com idades entre 3 e 16 anos, chegavam diariamente de canoa, ou após longa caminhada, por volta das seis, sete horas da manhã e só iam embora à noite. Partindo de seus interesses, Armanda levava-as a manipular objetos concretos: conchas, pedrinhas, folhas, frutos, retalhos de tecidos diversos, convertidos em material didático. Tentava, dessa forma, apostar na capacidade de pensar da própria criança, tomando como ponto de partida seu universo, sua experiência. (MIGNOT, 2010, p. 54)

Dessa maneira, Armanda dava início ao magistério, buscando dar sentido para sua vida em um momento no qual as mulheres adotavam, além da sagrada missão de mães, a tarefa de missionárias da nação, por meio do ministério de ensinar. Ela foi uma mulher apaixonada pela educação e procurou viver o magistério “[...] como um meio de afirmação pessoal e profissional, resultante de uma vontade de atuar no mundo, provocar mudanças e conferir sentido à própria existência” (MIGNOT, 2010, p. 54).

A educadora realizou empreendimentos inovadores na área educacional, projetando-se no mundo educacional de maneira ativa. Em 1921, Armanda iniciou as atividades da Escola Proletária de Meriti, posteriormente, Escola Regional de Meriti. Dois anos depois, ocupou a vice-presidência da Liga Brasileira Contra o Analfabetismo, que tramava e fortalecia a ideia de que a escola era a instituição capaz de suscitar o progresso. Em 1924, participou da fundação da Associação Brasileira de Educação (ABE). No ano seguinte, viajou à Europa para estudar em Genebra, no Instituto Jean Jacques Rousseau. De volta ao Brasil, presidiu a Seção de Cooperação da Família, da ABE, sendo que em 1930, liderou o “Memorial aos Editores Brasileiros” (MIGNOT, 2010). 
Armanda também Participou do I Congresso Internacional Feminista, realizado no Rio de Janeiro, que pretendia encaminhar ao chefe do governo as reivindicações das mulheres para o pleno exercício da cidadania, direito de voto, aumento das oportunidades educacionais, cancelamento da incapacidade civil da mulher casada. Em 1932, assumiu a presidência da $\mathrm{ABE}$, juntamente com Afrânio Peixoto, tendo a oportunidade de assinar o Manifesto dos Pioneiros da Educação Nova, objeto deste estudo, com o propósito de determinar diretrizes para a educação nacional. No Conselho Diretor da ABE, junto com Edgar Sussekind de Mendonça e Francisco Venâncio Filho, a educadora defendeu uma postura de neutralidade política e religiosa da entidade (MIGNOT, 2010).

Por suas lutas políticas em favor da educação laica e dos direitos da mulher, a imprensa nacional considerou Armanda subversiva e comunista, juntamente com seu marido, Edgar Süssekind de Mendonça, com o qual era casada desde 1928. Edgar era um professor que compartilhava das convicções políticas de sua esposa e trabalhavam juntos desde os tempos do colégio Jacobina, na Escola Regional de Meriti, quando ele foi um dos primeiros cooperadores, bem como na Associação Brasileira de Educação, da qual foram sócios-fundadores.

As acusações resultaram na prisão de Armanda, por oito meses, na Casa de Detenção do Rio de Janeiro. Em seu retorno à liberdade, viveu momentos difíceis, pois Edgar foi exonerado de seu cargo de professor do Instituto de Educação. Mas, mesmo em tempos de turbulência, Armanda continuou atuando; incentivou o Clube de Leitura da escola, que passou a realizar reuniões aos sábados, a fim de atender antigos alunos e moradores. Ela também articulou uma conferência sobre o papel da mulher judia no movimento sionista, durante a cerimônia comemorativa do primeiro aniversário do Estado de Israel; representou a Associação Brasileira de Educação na organização do III Congresso Infanto-Juvenil de Escritores; participou da solenidade organizada para comemorar o vigésimo aniversário de lançamento do Manifesto dos Pioneiros da Educação Nova, na sede do Ministério da Educação (MIGNOT, 2010).

Armanda também assinou parecer intitulado A Associação Brasileira de Educação e o Ensino Público elaborado por uma comissão designada pelo Conselho Diretor da ABE; subscreveu o Manifesto dos Educadores Democratas em Defesa do Ensino Público - Mais 
uma vez convocados - Manifesto ao povo e ao governo, lançado por ocasião da tramitação da Lei de Diretrizes e Bases da Educação Nacional; recebeu o Diploma de Membro Vitalício do Conselho Diretor da Associação Brasileira de Educação, pelos relevantes serviços prestados à educação e à entidade, homenagem da ABE pelos 40 anos da Escola Regional de Meriti.

Em 1962, Armanda participou da cerimônia comemorativa dos 30 anos do Manifesto dos Pioneiros da Educação Nova, na sede da ABE, solenidade que contou com o depoimento pessoal de Nóbrega da Cunha, intitulado "Ano da grande confusão nacional". Na ocasião, Fernando de Azevedo proferiu uma conferência em que recordava sobre a decisão pessoal e de seus companheiros, de lançar um documento ao povo e ao governo, o qual resultou em uma nova perspectiva à educação brasileira (MIGNOT, 2010).

No dia 5 de fevereiro de 1974 cala-se a voz da pioneira; morre Armanda Álvaro Alberto, deixando seu legado para a educação brasileira e, de forma particular, para todas as mulheres, no que diz respeito à luta pela democracia e pela liberdade.

\section{Considerações finais}

O presente estudo pondera a respeito do Manifesto dos Pioneiros da Educação Nova de 1932, importante documento que mudou o rumo da história da educação no Brasil e que contou com a assinatura de vinte e seis importantes intelectuais da época, analisando o papel feminino na cena histórica proposta à reflexão, já que, entre os signatários, existiam três mulheres que deixaram suas marcas na História da Educação.

Para o feito, recorreu-se à investigação bibliográfica, por meio de pesquisas em livros, artigos científicos e sites da internet. Assim, os resultados estimados sugerem que as pioneiras do Manifesto foram mulheres que estiveram à frente de seu tempo. Trata-se de um período histórico em que se aceitava a "Mulher do Lar", e que pessoas do gênero feminino eram vistas apenas no âmbito das relações pessoais e domésticas, as quais não precisavam e nem deveriam se envolver com questões políticas, educacionais, culturais ou sociais. Apesar desse cenário, três mulheres se destacaram e foram signatárias do Manifesto dos Pioneiros. Foram elas: 
Noemy Marques da Silveira Rudolfer: convidada por Fernando de Azevedo para subscrever o Manifesto, dirigiu serviços de orientação educacional da Fundação Getúlio Vargas e de outras importantes instituições de ensino no Rio de Janeiro; desempenhou missões culturais em vários países da América Latina, além de manter contatos pessoais com grandes líderes da ciência psicológica em visita a diversos países da Europa; mesmo depois de aposentada, continuou proferindo palestras e escrevendo artigos científicos, totalizando 200 publicações.

Cecília Bernevides de Carvalho Meireles: dirigiu a "Pagina de Educação", no Jornal Diário de Notícias do Rio de Janeiro e, mesmo antes do lançamento do Manifesto dos Pioneiros, a intelectual se utilizava do espaço do jornal para apoiar a Reforma de Fernando de Azevedo no Distrito Federal, defendendo a necessidade de inovação no entendimento educacional; criou a primeira e inovadora biblioteca infantil do Rio de Janeiro; viveu intensamente a literatura e educação no Brasil e em diversos países americanos, europeus, africanos e asiáticos; na condição de jornalista e educadora, registrou impressões e críticas sobre os acontecimentos sociais, destacando-se como uma pessoa ativa ao lado dos intelectuais do momento.

Armanda Álvaro Alberto: estudou em Genebra no Instituto Jean Jacques Rousseau; participou ativamente do processo de fundação da Associação Brasileira de Educação (ABE), tornando-se presidente em 1932, quando o Manifesto dos Pioneiros foi assinado; participou do I Congresso Internacional Feminista realizado no Rio de Janeiro, que pretendia encaminhar ao chefe do governo as reivindicações das mulheres para o pleno exercício da cidadania, tais como direito de voto, aumento das oportunidades educacionais, entre outros; chegou a ficar presa por oito meses na Casa de Detenção do Rio de Janeiro, por ser acusada de subversão e comunismo, devido à sua luta política em favor da educação laica e dos direitos das mulheres.

Observa-se o que há em comum entre as três mulheres que assinaram o Manifesto dos Pioneiros: o envolvimento com a área da educação e de questões sociais; experiências educacionais e profissionais fora do Brasil; a paixão pela educação; entre outros aspectos.

Ao refletir sobre a presença feminina no Manifesto dos Pioneiros, tornam-se evidentes as marcas do tempo em que viveram e, nessa direção, o Manifesto esteve 
presente e ajudou a desenhar as iniciativas, as escritas, os desejos das signatárias, que conseguiram transpor as barreiras de serem apenas esposas, mães e senhoras do lar, quer seja por necessidade ou decisão própria, a fim de conquistar um espaço maior na sociedade. Consequentemente, as três mulheres e educadoras destacadas neste estudo, conquistaram o reconhecimento social, ocuparam cargos que somente homens havia ocupado na esfera pública e deixaram seu legado para a História, principalmente para a sociedade brasileira.

\section{Referências}

BELO, Raquel Pereira; CAMINO, Leôncio. Analysis of discursives repertories about professions and gender: an empirical study in João Pessoa, Psicologia \& Sociedade, Porto Alegre, v. 22, n. 1, p. 23- 31, 2010.

GROMOWSKI, Vanderléia, SILVA, Jayme Aires da. Psicomotricidade na Educação Infantil. Janeiro, 2014. Disponível em: <https://psicologado.com/atuacao/psicologiaescolar/psicomotricidade-na-educacao-infantil>. Acesso em: 17 abr. 2019.

LEMME, Paschoal. O manifesto dos pioneiros da educação nova e suas repercussões na realidade educacional brasileira. Revista Brasileira de Estudos Pedagógicos, Brasília, maio/ago. 1984.

MIGNOT, Ana Chrystina Venancio. Armanda Alberto. Recife: Fundação Joaquim Nabuco: Editora Massangana, 2010. 164 p. (Coleção Educadores).

MORAES, José Damiro de. Trajetórias das signatárias do manifesto dos pioneiros: visões do escolanovismo nos anos 1930. Brasília, DF: Universidade de Brasília Disponível em: <http://www.sbhe.org.br/novo/congressos/cbhe5/pdf/974.pdf>. Acesso em: 20 de jan. 2017.

NAHES, Semiramis. Revista FON-FON: a imagem da mulher no Estado Novo (1937-1945). São Paulo: Arte \& Ciência, 2007.

OLIVEIRA, Marco Aurélio Gomes de. A concepção de infância presente no manifesto dos pioneiros da educação nova 1932: a presença do pensamento de John Dewey. Uberlândia: Navegando Publicações, 2016. 
PIMENTA, Jussara Santos. Pavilhão Mourisco: biblioteca e educação em Cecília Meireles. $24^{\mathrm{a}}$ Reunião Anual da ANPEd. Caxambu, MG, 2001. Anais... Disponível em:

<http://www.anped.org.br/sites/default/files/gt02_01.pdf>. Acesso em: 17 abr. 2019.

RAMOS, Aidyl de Queiróz Perez. Noemy da Silveira Rudolfer. Boletim Academia Paulista de Psicologia, São Paulo: Academia Paulista de Psicologia, v. 25, n. 2, maio/ago., p. 40- 44, 2005 .

RUIZ, João Álvaro. Metodologia científica. 5. ed. São Paulo: Atlas, 1996.

SAVIANI, Dermeval. História das idéias pedagógicas no Brasil. Campinas: Autores

Associados, 2007.

SCHWARTZMAN, Simon; BOMENY, Helena Maria Bousquet; COSTA, Vanda Maria Ribeiro. Tempos de Capanema. São Paulo: Paz e Terra: Fundação Getúlio Vargas, 2000.

XAVIER, Libânia Nacif. Para além do campo educacional: um estudo sobre o Manifesto dos Pioneiros da Educação Nova (1932). Bragança Paulista: EDUSF, 2002.

ZIMMERMAN, David. E. Psicanálise - perguntas e respostas: verdades, mitos e tabus.

Porto Alegre: Artmed, 2005.

Recebido em: 21/09/2017

Revisões requeridas: 04/04/2018

Aprovado em: 07/08/2018

Universidade do Estado de Santa Catarina - UDESC Programa de Pós-Graduação em Educação - PPGE

Revista Linhas

Volume 20 - Número 43 - Ano 2019

revistalinhas@gmail.com 